\title{
EEN STUDIEREIS NAAR DE WEST
}

MR. DR. L. N. DECKERS

III

\section{VENEZUELA}

De reis van Trinidad naar Venezuela maakte ik met de Surinamelijn van de K.N.S.M. Dit gaf mij het voordeel, dat ik reeds in Venezuela een kijkje kon nemen voordat ik te La Guaira, de haven van de hoofdstad Carácas, het schip voor goed zou verlaten.

Het gedeelte van Venezuela, dat zich uitstrekt van de Golf van Paria tot Carácas, wordt „El Oriente” genoemd en is een bezoek overwaard.

De eerste haven, welke men aandoet, is Carúpano, een onaanzienlijk plaatsje, met schamele woningen, veelal opgetrokken uit leem. De enkele straten, die Carúpano telt, zijn niet of slecht geplaveid en dienen tot wandel- en speelterrein van de hél luchtig gekleede jeugd en talrijke huisdieren, onder welke het varken domineert. Het land is dor en droog en slechts hier en daar op primitieve wijze eenigszins in cultuur gebracht. Een overeenkomstigen indruk krijgt men van alle havenplaatsjes tusschen Port of Spain en La Guaira. De streek is arm; de outillage van de havens kon veel beter zijn en het land is onvruchtbaar. Daarnaast krijgt men echter nog een anderen indruk; dien van de hartelijke gastvrijheid der bevolking en van de vereering, die zij den Liberator, haren grooten vrijheidsheld, Simon Bolívar, toedraagt. Geen plaatsje, hoe nederig ook, heb ik in Venezuela bezocht, of ik vond er een gedenkteeken, een plein, een straat, waaraan de naam van Bolívar is verbonden. Meermalen geen kerk en al evenmin een school, maar het beste wat men bezat in het sobere geheel had men den Bevrijder toegewijd. Ook moet ik hier vermelden, en ik doe het met groote waardeering, dat ik in alle havens, waar wij binnenliepen, aan boord een beleefdheidsbezoek mocht ontvangen van enkele autoriteiten, die mij in opdracht van de centrale Re- 
geering kwamen verwelkomen en nooit nalieten van hun eerbied en hoogachting voor Nederland te gewagen. $\mathrm{Zij}$ gaven zich verder alle moeite om mij zoo veel mogelijk van het havenplaatsje en zijn omgeving te laten zien. Op twee wijzen wordt de bezoeker van Venezuela telkens herinnerd aan de jaren van het Spaansche bewind. Ten eerste door de taal en de tallooze Spaansche namen van plaatsen en rivieren; ten tweede door de Spaansche zwier en hoffelijkheid van de bevolking.

Van Carúpano zet het schip koers naar het visscherseiland Isla de Margarita, bekend door de parels, welke er worden gevonden. $\mathrm{Na}$ eenig oponthoud ter reede van Pampatar, wordt de reis voortgezet naar Cumaná, gelegen aan de uitmonding van de Manzanares.

Te Cumaná had in de club een officieele ontvangst plaats, waarbij het niet ontbrak aan toespraken en wat nog meer bij zulk een plechtigheid behoort, en al evenmin aan belangstellende toeschouwers. Naar boord vergezelde mij een pak te Cumaná gemaakte sigaren van inlandsche tabak. De inhoud was veel grooter dan noodig mocht worden geacht voor de kennismaking met dit lang niet te versmaden Venezolaansche product.

De volgende haven van El Oriente is Guanta, dat bereikt wordt na enkele uren varens langs landtongetjes heen en tusschen kleine eilandjes door. Van het schip af heeft men een mooi gezicht op den bergrug, die zich uitstrekt langs Venezuela's kust. Te Guanta staan slechts enkele huizen, maar alleen reeds het indrukwekkend palmenbosch, in de onmiddellijke nabijheid gelegen, is het bezoek ten volle waard.

Per auto wordt een tochtje gemaakt naar Barcelona, de bescheiden hoofdstad van een der Venezolaansche Staten. Men vindt er een fraai aangelegd plantsoen, waarin met zorg bewaarde bouwvallen de herinnering levendig houden aan den strijd, door vorige geslachten hier gevoerd. Van die strijden hebben er, zoowel plaatselijk als gewestelijk, en ook nationaal vele gewoed in Venezuela en zij hebben er veel toe bijgedragen om het schoone land terug te houden van de welvaart en de economische ontwikkeling, waartoe het in andere omstandigheden, o.a. door zijn vele bodemschatten, zeker had kunnen komen.

$\mathrm{Na}$ Guanta te hebben verlaten stevent het schip naar Venezuela's zeer bekende haven, La Guäira. Hier behoeven wij niet op de reede te meeren. De haven is niet groot, maar heeft een ook voor zeeschepen voldoende diepte en wordt door een flinken golfbreker beschermd. Bovendien zijn de plannen gereed om 
haar een belangrijke uitbreiding te doen ondergaan en het zijn Nederlanders, die dit mooie werk zullen uitvoeren.

De tocht van La Guaira naar Carácas, die per auto anderhalf uur vordert, is een onafgebroken natuurgenot. De in technisch opzicht zeer goede weg slingert zich in vele bochten door het gebergte heen. Telkens opnieuw heeft men de schitterendste uitzichten op dalen en zee en geboomten, met daartusschen prachtige plekken van roode aarde en veelkleurige bloemen. De weg stijgt tot Ojo de Agua en voert vervolgens, al dalende, door Caracas' voorstadje Catia, over de Bolívar Avenue naar de Venezolaansche hoofdstad. Dat is een tocht om nooit te vergeten. Men moet het den Venezolanen nageven, dat zij hebben gezorgd voor een indrukwekkenden toegangsweg van zee naar hun metropool.

Carácas, $900 \mathrm{~m}$ boven den zeespiegel gelegen, heeft een oud en een nieuw stadsgedeelte. Het oude deel dagteekent uit de zestiende eeuw, dus den kolonialen tijd en schijnt geheel gerangschikt te zijn rondom de Plaza Bolívar, in het midden waarvan het groote ruiterstandbeeld verrijst van Venezuela's nationalen held. Het plein is omzoomd door kloeke boomen en deze dragen een bekoorlijken last van schitterende orchideeën. Om de Plaza Bolívar heen staan de Regeeringsgebouwen en de kathedraal. In het Pantheon bevindt zich een marmeren praalgraf van Simon Bolívar en andere helden uit den onafhankelijkheidsoorlog.

Het nieuwe gedeelte van Carácas is ruim aangelegd. Mooie boomen en parken vormen de sierlijke omlijsting van vele moderne woonhuizen, omringd door welverzorgde tuinen en met een patio in het midden. De voornaamste villawijk is El Paraiso. Hier vindt men ook de meeste Legaties, o.a. de Nederlandsche, welker hotel zich in waardigheid van voorkomen gerust met de andere Gezantschapsgebouwen mag meten.

Venezuela - Estados Unidos de Venezuela - heeft een oppervlakte van ongeveer $1.000 .000 \mathrm{~km}^{2}$, is dus dertig maal zoo groot als het Europeesche deel van het Nederlandsche Rijk. Het heeft $31 / 2$ millioen inwoners, voor $90 \%$ Mulatten en Zambos. De Europeanen en de Creolen - in het land zelf geboren blanken - maken samen $2 \%$ van de bevolking uit; de Indianen eveneens $2 \%$.

Op Carácas, dat 200.000 inwoners telt, volgt in belangrijkheid de oliestad Maracaibo, met 100.000 inwoners, de hoofdstad van den Staat Zulia. Daarna komen Valencia en Barquisimeto, elk met 50.000 inwoners, hoofdsteden der Staten Carabobo en Lara.

Venezuela werd in 1498 door Columbus ontdekt en ontleent zijn 
naam, Klein Venetië, aan een op palen gebouwd kunstdorpje, dat bij de zeevaarders herinneringen aan de schoone Dogenstad moet hebben opgeroepen. De nadere kennismaking met Europa was voor Venezuela niet bijster gelukkig. Karel V gaf het gebied in 1528 aan een bankiershuis in pand en de pandhoudster moet land en bewoners met ruw geweld hebben doen uitzuigen. Aan de daarmede samengaande misbruiken maakte Karel V een einde door het pand in te lossen en in 1550 het Spaansch kapiteingeneraalschap Carácas te stichten. De Spanjaarden hebben weinig gedaan om het door de natuur zoo rijk bedeelde land tot ontwikkeling te brengen. Wel spanden Spaansche missionarissen zich op onbaatzuchtige wijze in om de bevolking te kerstenen, maar wat van de zijde der Spaansche Regeering en derden geschiedde, was stellig niet allereerst gericht op de belangen van de bewoners der kolonie. Verbitterd door de stiefmoederlijke behandeling, kwam Venezuela in 1797 in opstand tegen Spanje, maar de verzetspoging faalde. Een tweede opstand, die van 1806, werd eveneens onderdrukt. Eerst toen de Venezolanen ten derden male naar de wapenen grepen, onder aanvoering van Generaal Simon Bolívar, behaalden zij na fellen, maandenlangen strijd de overwinning. In Juli 1811 riep Venezuela zijn onafhankelijkheid uit. In het uitgestrekte gebied duurde de oorlog inmiddels voort. Nog tweemaal, in 1811 en in 1814 wisten de Spanjaarden hun gezag te herstellen, doch beide keeren gelukte het den Venezolanen, onder leiding van Bolívar, het juk af te werpen. In December 1819 vereenigden Venezuela, Nieuw-Grenada en Quito zich tot den Bondsstaat Columbia, maar nog gaf Spanje den strijd niet op. Dit gebeurde eerst, nadat de Spanjaarden in 1821 bij Carabobo een beslissende nederlaag hadden geleden. Formeel heeft Spanje zich zijn rechten nog eenige jaren voorbehouden, tot het eindelijk in 1845, bij het Verdrag van Madrid, Venezuela's onafhankelijkheid erkende.

Inmiddels hadden in 1830 de drie den Bondsstaat Columbia vormende Staten zich van elkander losgemaakt en was Venezuela dus geheel zelfstandig geworden. Volkomen rijp voor zelfstandigheid, zeker voor deelneming van het volk aan wetgeving en bestuur, was het land echter nog geenszins. Gedurende de 19de eeuw was Venezuela voortdurend het tooneel van burgeroorlogen, strijd tusschen blanken en kleurlingen, strijd tusschen Unitariërs en Federalisten. De nieuwe grondwet van 1864, welke tot stand kwam, nadat generaal Falcon, de aanvoerder van de Federalisten, aan de macht was gekomen, maakte Venezuela tot een 
Statenbond. Het intreden der rust beteekende dit echter nog in geenen deele. Maar de staatsvorm bleef sindsdien gehandhaafd.

Tegenwoordig is Venezuela samengesteld uit: $a$ ) het Bondsdistrict met Carácas; $b$ ) twintig Staten; $c$ ) twee territoriën, te weten Amazones en Delta.

De wetgevende macht berust bij het Congres, samengesteld door den Senaat en de Kamer van Volksvertegenwoordigers. Het Congres kiest den President, telkens voor zeven jaren.

Reeds sinds 1721 bezit Carácas een universiteit. Ook heeft het een technische hoogeschool. Een tweede universiteit vindt men te Merida.

Wettelijk bestaat de leerplicht in Venezuela reeds sinds 60 jaren. Niettemin laat het schoolbezoek nog veel te wenschen over. Gaat men de oorzaken van dit verschijnsel na, dan vindt men als eerste de omstandigheid, dat er te weinig lagere scholen zijn. Ik wees er reeds op, dat er dorpen worden aangetroffen, waar het lager onderwijs nog niet zijn intrede heeft gedaan. Geen wonder, dat het aantal analfabeten groot is, veel grooter dan degene, die alleen met Carácas heeft kennis gemaakt, zou veronderstellen. Ik vond op een statistiek zelfs het percentage 75 vermeld.

De bezoeker van tegenwoordig zal tot de slotsom komen, dat het huidig bewind zich moeite geeft om Venezuela in cultureel en economisch opzicht vooruit te brengen. Veel is er nog te doen en groot zijn de mogelijkheden. Goed bestuurd, kan Venezuela, welks inkomsten thans bijna uitsluitend bestaan uit de opbrengsten van de concessies en de invoerrechten, tot de zeer welvarende landen gaan behooren. Onder het langjarig bewind van President Gomez, die niet door onbaatzuchtigheid heeft uitgemunt en vele goede krachten, die het land uitstekende diensten hadden kunnen bewijzen, doch tot de politieke tegenstanders behoorden, uit Venezuela de wijk deed nemen, had zeker meer voor de ontwikkeling van land en volk kunnen worden gedaan. Tot Gomez' verdiensten moet men intusschen rekenen, dat hij de goede verhoudingen met onderscheidene Staten - Groot-Brittannië, Frankrijk, Nederland, Italië, Vereenigde Staten - die onder zijn voorganger, President Castro, veel hadden geleden, heeft weten te herstellen. Eenige goede wegen - stellig nog lang niet genoeg werden onder hem aangelegd; de sociale wetgeving en overheidszorg voor de volksgezondheid werden geïntroduceerd.

Eleazar Lopez Contreras, Minister van Oorlog onder het presidentschap van Gomez, volgde dezen in 1935 op. Steunend op het vertrouwen van velen, die hem reeds voorheen om zijn be- 
langeloozen arbeid bijzonder waardeerden, streeft deze President van de Vereenigde Staten van Venezuela naar den economischen opbloei en de cultureele ontwikkeling van het schoone en rijke land, dat in hem zijn oppersten leidsman heeft.

De Regeering heeft een driejarenplan vastgesteld, waaromtrent in „Economische Voorlichting" 1) het volgende wordt medegedeeld.

Het plan loopt over het tijdvak van 1 Juli 1938 tot 30 Juni 1941 en omvat de besteding van 1200 millioen bolivars voor opvoeding, immigratie, hygiëne, havens, spoorwegen, wegen en andere openbare werken.

Momenteel is de bestudeering van de volgende plannen beëindigd: haven van La Guaira; spoorweg El Palito-Palma Sola; kaden van Maracaibo en La Vela; zoutontginning Araya en verschillende waterleidingen. Met deze werken kan nog in 1938 een aanvang worden gemaakt.

De oprichting van hotels in badplaatsen ter aanmoediging van het toerisme kan in 1939 beginnen.

Met betrekking tot de zandbank van Maracaibo zal het Gouvernement beginnen met een geul te laten baggeren voor schepen van 12 voet diepgang. De verwachting is, dat in het midden van 1939 definitief zal zijn voorzien in een voldoende gemeenschap van Maracaibo met de Open Zee.

Verder is nog de oprichting van kaden te Carúpano, Puerto Sucre en Ciudad-Bolívar in studie.

Met betrekking tot de spoorwegen hoopt het Gouvernement in 1939 vier concrete plannen bij het Parlement in te dienen, te weten: de verlenging van den Táchzia-spoorweg naar San Christobal, het aanleggen van een zijtak aan de lijn Santa Barbara-El Vigia, het aanleggen van een spoorweg van San Christobal naar den bovenloop van de Apure en de verlenging van den Centralen spoorweg naar de Staten Guárico en Apure. Verder hecht het Gouvernement groote beteekenis aan den aanleg van een spoorweg van de Orinoco naar de mijnstreken van Venezolaansch Guyana, waarvoor de kosten zijn begroot op 15 millioen bolivars. Het kan echter zijn, dat samenwerking met de betrokken mijnmaatschappijen het Gouvernement in staat zal stellen het beraamde plan te verwezenlijken, zonder dat het een zoo groote som behoeft te besteden.

Het noordelijk deel van Venezuela is het meest in cultuur ge-

1) 16 September 1938, blz. 1380 . 
bracht en de mais is het belangrijkste product. Zij vormt het voornaamste volksvoedsel. Drie maisoogsten per jaar zijn geen uitzondering.

Verdere landbouwvoortbrengselen van beteekenis zijn koffie en cacao, - het eerste koffiedistrict van Venezuela ligt niet ver ten zuiden van Carácas en is langs een goeden weg te bereiken - tabak, suiker, rijst en katoen, tonkaboonen, rubber, cocosnoten en copra. Ook de veeteelt is van belang. In Venezuela vindt men groote grasvlakten, de z.g. llano's, die aan overstroomingen bloot staan en mede daardoor alleen voor veeteelt worden aangewend.

De belangrijkste mineralen zijn goud, koper, zilver, ijzer, asfalt en de laatste jaren vooral olie.

Naar blijkt uit een mededeeling ${ }^{1}$ ) van $\mathrm{Hr}$. Ms. Gezant te Carácás, was over het eerste halfjaar van 1938 de buitenlandsche handel van Venezuela, blijkens een onlangs gepubliceerde Venezolaansche statistiek, als volgt 2):

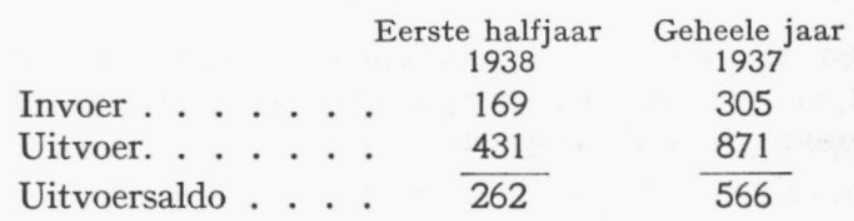

De invoer bestond hoofdzakelijk uit machines voor de petroleumwinning, en voorts uit voedingsmiddelen (16 millioen $\mathrm{Bs}$ ) en textielgoederen (eveneens 16 millioen Bs.) De uitvoer had voor Bs 399 millioen (geheel 1937: Bs 770 millioen) betrekking op petroleum; voorts ongeveer Bs 17 millioen aan koffie, Bs 6 millioen aan ongemunt goud en Bs 4 millioen aan cacao, tegen in het geheele jaar 1937 resp. 38, 36 en 14 millioen bolivars.

De invoer uit Nederland heeft Bs 9 millioen, de uitvoer naar Nederland Bs 0,4 millioen bedragen, tegen in geheel 1937 resp. 17 en 3 millioen bolivars. Met betrekking tot Curaçao en Aruba gezamenlijk waren die cijfers resp. 1,3 en 320 millioen bolivars, tegen in geheel 1937: 1,7 en 629 millioen. De uitvoer naar die eilanden bestaat vrijwel uitsluitend uit petroleum.

1) Opgenomen in Economische Voorlichting van 24 Februari 1939, blz. 318.

2) In millioenen bolivars, ter waarde van Bs 1,785 = f 1 . - op 1 Januari 1938 en Bs $1,77=\mathrm{f} 1$. - op 30 Juni 1938. Ter vergelijking zijn de cijfers over het geheele jaar 1937 erbij vermeld. De cijfers zijn afgerond. 
Onder de petroleum produceerende landen neemt Venezuela thans de derde plaats in. Op de eerste en de tweede plaats komen de Vereenigde Staten en Rusland. De ontwikkeling van de petroleumnijverheid, geheel gedreven met buitenlandsch kapitaal, is bijzonder snel in haar werk gegaan. Onderstaande cijfers, aangevend wat Venezuela in de jaren 1917-1937 aan petroleum produceerde, toonen den ontwikkelingsgang aan.

$\begin{array}{cccc}\text { Jaar } & \begin{array}{c}\text { Opbrengst in } \\ \text { 1000-tallen barrels }\end{array} & \text { Jaar } & \begin{array}{c}\text { Opbrengst in } \\ \text { 1000-tallen barrels }\end{array} \\ 1917 & 119 & 1932 & 116.565 \\ 1920 & 1.576 & 1933 & 119.004 \\ 1924 & 8.754 & 1934 & 137.985 \\ 1928 & 106.500 & 1935 & 148.529 \\ 1929 & 137.473 & 1936 & 155.229 \\ 1930 & 136.992 & 1937 & 187.701 \\ 1931 & 117.123 & & \end{array}$

Dat Venezuela's betalingsbalans met een groot exportsaldo sluit, is geheel aan den uitvoer van petroleum te danken. De exportsaldi waren de volgende:

$\begin{array}{cccc} & 1000 \text { bolivars } & & 1000 \text { bolivars } \\ 1913 & 59.346 & 1935 & 486.536 \\ 1933 & 473.959 & 1936 & 556.873 \\ 1934 & 512.257 & 1937 & 566.400\end{array}$

Uit de cijfers, welke thans volgen, blijkt het belangrijk aandeel, dat de petroleum-uitvoer heeft in den totalen uitvoer. Tevens toonen zij aan, dat zonder uitvoer van olie, het exportsaldo van de betalingsbalans in zijn tegendeel zou verkeeren.

\begin{tabular}{lccr} 
Jaar & $\begin{array}{c}\text { Uitvoer van } \\
\text { petroleum }\end{array}$ & $\begin{array}{c}\text { totaal } \\
\text { uitvoer }\end{array}$ & invoer \\
& \multicolumn{3}{c}{ In 1000 bolivars } \\
1913 & - & 152.766 & 93.420 \\
1933 & 557.446 & 617.546 & 43.500 \\
1934 & 557.243 & 617.943 & 159.700 \\
1935 & 654.330 & 711.730 & 225.200 \\
1936 & 685.963 & 768.463 & 211.600 \\
1937 & 772.000 & 871.000 & 304.600
\end{tabular}


Het centrum van de petroleumwinning is Maracaibo, gelegen in het noordwesten, aan de zee-engte, welke de Golf van Venezuela met het Meer van Maracaibo verbindt. Ik had het voorrecht van Curaçao uit met een vliegtuig van de K.L.M. naar Maracaibo te gaan. De stad naderend, ziet men tallooze boortorens verrijzen, niet alleen op het land, maar ook in het water. Hoogst belangwekkend was de tocht per vliegtuig van de Shell-directie over de olievelden van Cabimas, Lagunillas, Bachaquero en San Lorenzo, alle aan het Meer van Maracaibo gelegen en dan landwaarts over Mene Grande. Men krijgt aldus den besten indruk van den geweldigen omvang van het bedrijf. Voortdurend vervoeren zwaar beladen tankschepen de ruwe olie van Maracaibo naar de raffinaderijen van Curaçao en Aruba. In 1936 brachten 3546 tankers met een bruto-inhoud van 9.300 .000 registerton de ruwe olie van Maracaibo naar Curaçao en 2.740 tankers, met een bruto-inhoud van 7.140.000 registerton vervoerden het product van Maracaibo naar Aruba. In 1937 kwam 9.000 millioen $\mathrm{kg}$ ruwe olie uit Venezuela Curaçao binnen, voor een waarde van 90 millioen gulden en 13.000 millioen $\mathrm{kg}$ Aruba, een waarde vertegenwoordigend van 136 millioen gulden.

Het mooiste deel van Maracaibo is dat, waar de woningen werden gesticht van hen, die in de olie-ontginning werkzaam zijn. Hier vindt men moderne huizen, sportterreinen, ontspanningsgebouwen en niet te vergeten het voortreffelijke ziekenhuis, waaraan de naam van den Nederlandschen geneesheer Dr. van Tienhoven onafscheidelijk is verbonden.

Nog een anderen tocht in Venezuela moet ik vermelden. Van Carácas uit bezocht ik de „Estation Experimental de El Valle”, het centrale landbouwproefstation van Venezuela. Deze inrichting staat onder leiding van den Italiaanschen geleerde Dr. Augusto Bonazzi. Op elk gebied, dat op den landbouw betrekking heeft, worden hier onderzoekingen gedaan en men geeft zich alle moeite om te bevorderen, dat de landbouwende bevolking op den duur in haar bedrijf de vruchten van dezen arbeid zal plukken.

Een der assistenten van Dr. Bonazzi is een jong Zwitser, de heer Christoffel, die in België het diploma van landbouwkundig ingenieur behaalde. Hij werd mijn reisgenoot en tolk op den tocht, dien ik met kolonel Acosta, Chef van de Afdeeling „Immigratie en Kolonisatie" van het Ministerie van Landbouw, makte naar Chirgua. De reis ging per auto over Los Teques en 
Maracay, langs het schilderachtige Meer van Valencia, naar Valencia, de hoofdstad van den Staat Carabobo. Na een krans te hebben gelegd bij de pompeuze monumenten, opgericht ter plaatse, waar in 1821 de voor Venezuela's vrijheid beslissende slag van Carabobo werd geleverd, zette ik den tocht voort, over Rosario en Barreras, naar het dorpje La Mona, dat wij nog per auto konden bereiken. De afstand van La Mona naar Chirgua werd te paard afgelegd. Het kon bezwaarlijk anders, want de nieuwe weg naar de kolonie was, al werd er hard aan gewerkt, nog lang niet gereed en de oude, onverharde baan was voor elk voertuig, hoe sterk ook zijn motor mocht zijn, absoluut onberijdbaar. Ten slotte kwamen wij in Chirgua aan en wij vonden daar een zestigtal nette boerderijtjes, bestemd voor Deensche landbouwersgezinnen, die zich reeds hadden ingescheept en binnen een paar weken de woningen zouden betrekken. Een Deensche familie was al aangekomen: een flinke, ontwikkelde landbouwer, zijn vrouw - met beiden kon men zich gemakkelijk in de Engelsche taal onderhouden - en twee welopgevoede dochtertjes.

Alle woningen van de Deensche kolonie, benevens haar kerkje en haar school zijn van staatswege gebouwd. Bij iedere boerderij behooren een tuin en het noodige bouwland. Dit land is van goede kwaliteit. Tegen de hellingen der bergen vinden de landbouwers de weiden voor hun vee. In afwachting van de komst der immigranten waren voor elk gezin de aardappelen reeds gepoot. De nieuw-aangekomenen zouden ze kunnen oogsten. De kolonist kan eigenaar worden van zijn bedrijf door gedurende 18 jaren een zekere som te betalen. Het zal nuttig zijn, dat van Nederlandsche zijde met aandacht de ontwikkeling van deze Deensche kolonie in Venezuela wordt gevolgd. Het leven is duur in Venezuela. De export van landbouwproducten wordt bemoeilijkt door de zeer hooge valuta en de exportpremies, door de Regeering verleend, komen aan dit bezwaar niet ten volle tegemoet. De cultures van Denemarken verschillen veel met die van Venezuela en ook aard en karakter van den Deen vertoonen menig verschilpunt met die van den Venezolaan. Maar iedere kolonist weet nu eenmaal, dat hem in het nieuwe land vele en groote moeilijkheden wachten. Kolonel Acosta verzekerde mij, dat de boeren van Chirgua behoorlijk den kost zullen kunnen verdienen voor hun gezin en dat de Regeering hun alle hulp en voorlichting zal verleenen, ten einde de kolonisatie te doen slagen. Door deze kolonisatie en meer andere, welke in voorbereiding zijn, hoopt de Regeering te bereiken, dat landbouwers, die hun vak volkomen beheerschen en 
de moderne methodes verstaan, de bodemopbrengst van het land verhoogen, landbouw en veeteelt tot meer ontwikkeling brengen en bovendien, door hun voorbeeld, de vakkundigheid van de Venezolaansche boeren vergrooten.

Tegen het vallen van den avond werd de terugreis aanvaard en het was middernacht toen wij te Maracay aankwamen om daar in het schitterende hotel "Jardin" te overnachten. Jammer genoeg is dit hotel eenigszins in verval. Voor Maracay, met zijn 30.000 inwoners, is het veel te groot en te weelderig. Het werd gebouwd in den tijd van President Gomez, die aan zijn buitenlandsche en andere gasten een verblijf wilde geven, hunner waardig. Gomez verbleef veel liever en veel meer te Maracay dan in de hoofdstad. Hij stichtte er o.a. een model-boerderij en een dierentuin. Het waren de gouden jaren voor Maracay, dat toen dikwijls vreemde bezoekers had en........ groote feesten in zijn sprookjesachtig hotel. De dood van Gomez en het optreden van den huidigen President, die meestal in zijn paleis te Carácas verblijft, makten aan Maracays glanstijdperk een einde.

Flink aangelegd is de te Maracay gevestigde opleidingschool voor militaire vliegers. $\mathrm{Zij}$ beschikt over ruime gebouwen en uitgestrekte terreinen. Officieren van de Italiaansche luchtmacht treden als instructeurs op. Trouwens niet alleen aan dit moderne wapen schenkt de tegenwoordige Regeering alle aandacht. Te Carácas bracht ik een bezoek aan de Militaire Academie, waar officieren voor de landmacht worden opgeleid. Niet allen, maar zij, die bestemd zijn voor de belangrijkste posten. Groot is de school niet, maar de gebouwen zijn gerieflijk en hygiënisch ingericht en bij het onderwijs der cadetten wordt gebruik gemaakt van modern materiaal.

Te Maracay had ik gelegenheid tot het brengen van een bezoek aan het nationale park, gelegen aan het schoone Meer van Maracay. De figuren, aangebracht op de zuilen en terrassen, houden de herinnering levendig aan Venezuela's oudste bewoners, de Indianen, thans nog slechts schaars vertegenwoordigd.

Toen het verblijf te Maracay ten einde was geloopen, ging ik per auto, over den voortreffelijken, onder Generaal Gomez aangelegden weg La Guaira-Puerto Cabello, naar laatstgenoemde haven. Hier scheepte ik mij in op de „Colombia” van de K.N.S.M., die mij naar Curaçao zou brengen. 